\title{
DIREITO À DESCONEXÃO DO TRABALHO FRENTE A UMA SOCIEDADE HIPERCONECTADA
}

\section{Barbara Bedin ${ }^{1}$}

Resumo: Esse artigo propõe a análise do direito à desconexão, representada pelo direito ao descanso, ao lazer, à intimidade e à vida privada através da limitação da jornada de trabalho que ficou debilitada com o advento das tecnologias. Além de tratar sobre a regulamentação da utilização dos meios tecnológicos no ambiente de trabalho, tem o objetivo de identificar os males causados pelo excesso de trabalho e pela hiperconectividade a fim de justificar a importância da desconexão. Para tanto, utiliza-se o método de pesquisa bibliográfica.

Palavras-chave: Hiperconectividade; Desconexão; Jornada de Trabalho; Tecnologias; Direitos Fundamentais.

\section{RIGHT TO DISCONNECT WORK FROM A HYPERCONTRACTED SOCIETY}

\begin{abstract}
This article proposes the analysis of the right to disconnect, represented by the right to rest, leisure, intimacy and private life through the limitation of the working day that was weakened with the advent of technologies. Besides addressing the regulation of the use of technological means in the work environment, it aims to identify the evils caused by overwork and hyperconnectivity in order to justify the importance of disconnection. For this, the method of bibliographic research is used.
\end{abstract}

Keywords: Hyperconnectivity. Disconnection. Working Day. Technologies. Fundamental rights.

\footnotetext{
${ }^{1}$ Mestre em Direito do Trabalho. Doutora em Letras (Argumentação Jurídica no Direito do Trabalho). Email: barbara@prelum.com.br. End. Rua José Eberle, n. 982 - Térreo, Pio X, Cep. 95034-400, Caxias do Sul/RS
} 


\section{INTRODUÇÃO}

O artigo aborda uma discussão já antiga de direito - a jornada de trabalho excessiva frente aos direitos fundamentais do trabalhador, principalmente o direito ao lazer - através de uma expressão inovadora utilizada por Souto Maior que é o "direito à desconexão". A abordagem não se limita à regulação da utilização dos meios tecnológicos no ambiente de trabalho, mas também identificar os males causados pelo excesso de trabalho e pela hiperconectividade a fim de justificar o uso e aplicação daquele termo.

As relações trabalhistas foram fortemente impactadas e revolucionadas pelo processo de globalização, especialmente a partir da década de 1980, quando a tecnologia começou a interferir significativamente nos meios de comunicação. A incorporação definitiva das novas tecnologias às relações trabalhistas originou um novo comportamento e até mesmo novas formas de contratos laborais como o teletrabalho, que é uma tendência mundial e acabou por romper conceitos tradicionais de jornada, subordinação e fiscalização,

Com as novas tecnologias implantou-se, aparentemente, uma norma na cultura trabalhista brasileira de disponibilidade em tempo integral com a possibilidade de ser comunicado e executar as tarefas em qualquer lugar e a qualquer momento. Tal situação acaba por gerando uma série de consequências prejudiciais à saúde, à vida pessoal, social e familiar.

Nesse sentido, iniciou-se um movimento doutrinário de defesa ao direito de desconexão, a fim de assegurar aos trabalhadores os direitos de ordem social, que não permitem retrocesso. Afinal, as tecnologias se instalaram tão rapidamente que não houve tempo para instituir normas de utilização e acabou por predominar o seu uso abusivo, desordenado e caótico.

Dessa forma, pretende-se analisar os aspectos que compreendem o direito à desconexão para assimilar a sua importância. Especificamente, objetiva-se a) identificar as mudanças ocorridas nas relações de trabalho quanto ao uso da tecnologia; b) identificar a regulação do uso das tecnologias no ambiente de trabalho; c) analisar os demais direitos relacionados diretamente ao direito à desconexão d) analisar as consequências geradas pelo excesso de labor e pela hiperconectividade; e) compreender o direito à desconexão; f) analisar julgados referentes ao direito à desconexão para compreender a sua aplicação.

Para isso, se contextualiza as relações de trabalho frente às novas tecnologias, identificando a dignidade da pessoa humana, a intimidade e a privacidade e o direito ao lazer como institutos 
ameaçados perante esta nova realidade social. A fim de demonstrar a urgência e a importância da discussão a respeito do direito à desconexão, abordam-se situações preocupantes que são reflexos do excesso de labor e da hiperconectividade. Utiliza-se o método bibliográfico para a construção do artigo.

\section{A JORNADA DE TRABALHO, O TELETRABALHO E O INCISO III, DO ART. 62}

\section{DA CLT}

A jornada de trabalho é protagonista na história do desenvolvimento do Direito do Trabalho e, assim como o salário, é um dos assuntos centrais em controvérsias e litígios trabalhistas que conduziram "à construção e desenvolvimento do ramo juslaboral especializado do direito" (DELGADO, 2008, p. 832). No entanto, tratar sobre a jornada de trabalho não é o objetivo primeiro do artigo. Assim, presume-se que o leitor já se apropriou de conceitos e entendimento sobre a duração do trabalho, jornada de trabalho e horário de trabalho e relacionados.

Importante salientar que as regras de medicina e segurança do trabalho tratam não só dos períodos de trabalho e das condições de trabalho, mas também dos períodos de descanso que, para CASSAR (2017, p. 601) se fundamenta em três aspectos: biológicos, sociais e econômicos. A autora explica, sobre o fator biológico, que o excesso de trabalho causa "fadiga, estresse, cansaço ao trabalhador”, o que danifica sua saúde física e mental. Quanto ao aspecto social, ela afirma que a carga horária extensa esmaece a relação do trabalhador com a família e os amigos, excluindo-o socialmente. Por fim, em relação ao aspecto econômico, a autora argumenta que o cansaço e estresse gerados pelo excesso de trabalho resultam em baixa produtividade.

A jornada de trabalho ganhou visibilidade exatamente quando os estudos relacionados à saúde e segurança laborais avançaram e demonstraram que a jornada extensiva, em determinadas atividades, é definitiva para insalubridade (DELGADO, 2012, p. 863).

Essa política de saúde no trabalho foi firmada na Constituição, de modo exemplar, através do art. $7^{\circ}, \mathrm{XXII}^{2}$, que determina a diminuição dos riscos inerentes ao trabalho, através de normas relacionadas à saúde, higiene e segurança (DELGADO, 2012, p. 863). A duração do labor,

\footnotetext{
${ }^{2}$ Art. $7^{\text {o: }}$ "São direitos dos trabalhadores urbanos e rurais, além e outros que visem à melhoria de sua condição social: (...) XXII - redução dos riscos inerentes ao trabalho, por meio de normas de saúde, higiene e segurança;.
} 
semanal ou mensal, implica diretamente nas condições de trabalho na empresa, conforme Maurício Godinho Delgado (2012, p. 864) argumenta:

[...] a modulação da duração do trabalho é parte integrante de qualquer política de saúde pública, uma vez que influencia, exponencialmente, a eficácia das medidas de medicina e segurança do trabalho adotadas na empresa. Do mesmo modo que a ampliação da jornada (inclusive com a prestação de horas extras), acentua, drasticamente, as probabilidades de ocorrência de doenças profissionais ou acidentes de trabalho, sua redução diminui, de maneira significativa, tais probabilidades da denominada "infortunística do trabalho".

Além de acrescentar o fator humano devido aos acidentes de trabalho, NASCIMENTO (2013, p.299) afirma existir o fundamento político uma vez que é dever do Estado garantir "condições satisfatórias de vida e de trabalho como meio de plena realização dos objetivos políticos".

\section{O TELETRABALHO E O INCISO III, DO ART. 62 DA CLT}

Três são os elementos principais que caracterizam o teletrabalho: a) o uso das novas tecnologias de informática e telecomunicação; b) a redução ou até mesmo a ausência de contato com os colegas e superiores hierárquicos e; c) a alteração do local de trabalho que geralmente é a casa do trabalhador, mas também pode ser um outro local adotado por ele e por vezes, parcialmente, a sede da empresa. (VALENTIM, 1999, p. 526, apud CASSAR, 2017, p. 660).

A Lei $n^{\circ} 13.467 / 17$ conceituou e disciplinou o teletrabalho através dos arts. $75-B^{3}$ e $75-C^{4}$, introduzindo-o como inciso III $^{5}$ do art. 62 discutido até então. Ou seja, mesmo que possa ser controlado, o teletrabalho não terá direito à hora extra, intervalo intrajornada e entrejornada. No entanto, CASSAR (2017, p. 671) discorda da inclusão do teletrabalho no art. 62 da CLT:

\footnotetext{
3 "Considera-se teletrabalho a prestação de serviços preponderantemente fora das dependências do empregador, com a utilização de tecnologias de informação e de comunicação que, por sua natureza, não se constituam como trabalho externo.

Parágrafo único. O comparecimento às dependências do empregador para a realização de atividades específicas que exijam a presença do empregado no estabelecimento não descaracteriza o regime de teletrabalho."

4 "A prestação de serviços na modalidade de teletrabalho deverá constar expressamente do contrato individual de trabalho, que especificará as atividades que serão realizadas pelo empregado.

$\S 1^{\circ}$ Poderá ser realizada a alteração entre regime presencial e de teletrabalho desde que haja mútuo acordo entre as partes, registrado em aditivo contratual.

$\S 2^{\circ}$ Poderá ser realizada a alteração do regime de teletrabalho para o presencial por determinação do empregador, garantido prazo de transição mínimo de quinze dias, com correspondente registro em aditivo contratual."

5 “Art. 62 - Não são abrangidos pelo regime previsto neste capítulo: III - os empregados em regime de teletrabalho."
} 
[...] no passado era difícil a mensuração do trabalho de um empregado em domicílio. Mas diante das novas tecnologias que permitem, em tempo real, o contato entre o empregado e o patrão, este meio de trabalho tem sido mais controlado e fiscalizado. Absurdo, por isso, o comando legal que excluiu os teletrabalhadores de tantos benefícios pela mera presunção de que não são controlados.

Assim como Cassar, Souto Maior (2017, p. 05) manifesta a sua discordância com a inclusão dos teletrabalhadores no art. 62 da CLT:

\footnotetext{
No momento em que a jurisprudência tendia a limitar as possibilidades de aplicação do art. 62, que exclui alguns trabalhadores, de forma artificial e inconstitucional, do direito ao limite da jornada de trabalho, a "reforma" vem e não só reforça a aplicabilidade do art. 62, ampliando o seu alcance pela atração dos "empregados em regime de teletrabalho", cujo controle da jornada de trabalho é plenamente possível e isso em razão da própria evolução tecnológica em que se diz estar baseada a regulamentação desse tipo de trabalho.

O direito à desconexão é uma pauta em diversos países do mundo, como forma de evitar que o trabalho à distância tome conta da vida dos trabalhadores de maneira integral.
}

O parágrafo único do art. $6^{\circ}$ da CLT reconhece, inclusive, que os meios eletrônicos facilitam o monitoramento: "Os meios telemáticos e informatizados de comando, controle e supervisão se equiparam, para fins de subordinação jurídica, aos meios pessoais e diretos de comando, controle e supervisão do trabalho alheio.”. Importa frisar que, para a consideração do teletrabalhador no inciso III do art. 62, deve constar no contrato, uma cláusula expressa indicando a "modalidade de trabalho e especifique as tarefas que o empregado deve realizar" (CASSAR, 2017, p. 661).

\section{AS RELAÇÕES DE TRABALHO FRENTE AS TECNOLOGIAS DA GLOBALIZAÇÃO E OS DIREITOS FUNDAMENTAIS E SOCIAIS ATINGIDOS PELA HIPERCONECTIVIDADE}

Em que pese as divergências, existe o consenso de que a globalização é a palavra empregada para identificar a intensificação da inter-relação entre os Estados e suas realidades sociais, políticas, econômicas e culturais, criando a noção de um todo (DELGADO, 2015, p. 15-16).

Para Domenico De Masi (2000, p. 149), “a globalização atual representa somente o êxito mais elaborado de uma tendência perene do homem, de explorar e depois colonizar todo o território 
que ele pensa que exista, até construir uma única aldeia”, nesse sentido, a globalização não é novidade.

No entanto, foi no fim do século XX que o processo de globalização passou a ocorrer de modo extremamente acelerado devido aos avanços tecnológicos. A microinformática e a internet, surgidas nesta época, possibilitaram informação, análises e negociações simultâneas e imediatas, perdendo-se as noções de tempo e espaço de até então (DELGADO, 2015, p. 18-19). A globalização acelerou a economia engrandecendo os países que adotaram o capitalismo. Os produtores passaram a comprar matéria prima em qualquer lugar do mundo, instalar suas fábricas onde a mão-de-obra fosse mais barata e com mínima legislação social, vendendo suas mercadorias com as melhores condições de competição, para o mundo inteiro.

A realidade econômica é caracterizada pela competitividade extrema e, na estratégia pela sobrevivência, procuram-se métodos que resultem em maior produtividade e qualidade com os menores custos. Desta forma, o processo da globalização caracterizou-se pelo crescimento dos fluxos financeiros internacionais, aumento da concorrência, integração de economias e internacionalização dos produtos (CASSAR, 2010, p. 19-20).

Certamente a sociedade enfrenta a maior das revoluções, a revolução tecnológica que motivou mudanças sociais, econômicas, políticas e culturais. Além de proporcionar inúmeras melhorias e facilidades no cotidiano, exigiu-se uma adaptação do modo de vida da sociedade que, através da conexão, tem poder de alterar rapidamente os padrões sociais circulando informação, conhecimento e cultura (NAZIAZENO, 2012, s.p.).

No terceiro trimestre de 2015, o Brasil registrou o número de 76,1 milhões de pessoas que utilizam aparelho celular com acesso à internet. E crescimento do uso dos computadores com internet em casa: em setembro de 2000, 9,8 milhões de pessoas possuíam computador conectado em suas residências. Em 2015, são 95,6 milhões (NIELSEN IBOPE, 2015, s.p.).

Obviamente, a tamanha conexão da sociedade refletiu no tempo, no lazer e no trabalho. Sabese que o contrato de trabalho gera, inevitavelmente, um envolvimento que compromete além do profissional, o que ficou agravado com o uso das tecnologias (SUSSEKIND; MARANHÃO; VIANNA, 2002, p. 253), como afirma Almeida, Severo (2016, p. 40):

A relação de trabalho reflete, como não poderia deixar de ser, a sociedade e que ela se estabelece. Essa urgência da vida contemporânea invade o ambiente de trabalho para determinar a necessidade de especialização contínua, de controle contínuo, de 
conexão contínua. Isso, porém, tem consequências graves, que afetam diretamente a vida privada e social do empregado.

Por isso, origina-se a necessidade de respeito à personalidade do empregado e à sua dignidade, devendo existir um equilíbrio do poder diretivo em relação aos direitos e garantias do trabalhador, assegurando sua autonomia (SUSSEKIND; MARANHÃO; VIANNA, 2002, p. 253), como argumenta ROMITA (2005, p. 191):

O dever que tem o empregador de dispensar tratamento digno ao empregado está na raiz da obrigação de respeitar os direitos fundamentais do obreiro. Esta obrigação tem por conteúdo o respeito aos direitos inerentes à dignidade da pessoa, que se relacionam com os direitos fundamentais, considerados de maneira genérica.

As alterações ocorridas no modo de trabalhar, decorrentes das inovações tecnológicas, aumentaram a necessidade de reflexão quanto aos direitos fundamentais do empregado. Não se originou um novo direito, mas os direitos já existentes foram interpretados com novas funções e abrangência. O termo "desconexão", portanto, é utilizado para expressar o direito ao descanso, ao lazer, à intimidade e à vida privada através da limitação da jornada de trabalho que ficou debilitada com o advento das tecnologias ${ }^{6}$ (OLIVEIRA, 2010, p.1181). O direito à desconexão, portanto, é entendido como direito fundamental visto que, se não proporcionado, fere as garantias asseguradas exclusivamente ao trabalhador e demais direitos fundamentais e sociais contidos em diferentes diretrizes nacionais e internacionais. Nesse sentido, do direito à desconexão decorrem outros direitos do trabalhador como a a dignidade da pessoa humana, o direito à intimidade e à privacidade e também o direito ao lazer, uma vez que estão intimamente ligados à desconexão do trabalhador.

\subsection{Dignidade da Pessoa Humana}

O trabalho, conforme o entendimento dos autores Almeida, Severo (2016, p. 13-14), fornece subsistência material e constitui o ser social, garantindo, desde sempre, a sobrevivência do homem. O ser humano se sente, através do trabalho, inserido na comunidade como sujeito que se desenvolve e se identifica. Ou seja, o labor é importante para o desenvolvimento pleno do indivíduo, constituindo até mesmo sua perspectiva de sociabilidade que é intrínseca à condição

\footnotetext{
${ }^{6}$ Grifo nosso.
} 
humana. Por isso, tem-se que o trabalho é "elemento inafastável da dignidade da pessoa humana" (ALMEIDA, SEVERO, 2016, p. 13-14).

A dignidade da pessoa humana está expressa no artigo $1^{\circ}$, III, da Constituição como parâmetro do Estado Democrático de Direito. Suas definições ultrapassam o direito e possuem esfera moral, cultural, religiosa e filosófica. Trata-se de uma qualidade presente desde o nascimento (embora não seja uma qualidade biológica ou genética), que não pode ser vendida ou cedida uma vez que impossível sua coisificação ou materialização. Mesmo que habitualmente conceituada de forma subjetiva e abstrata, tem-se a certeza de que a dignidade é real e concreta já que frequentemente se verificam situações onde ela é violada (SARLET, 2007, pg. 362-365). Nesse mesmo sentido, Celina Bodin de Moraes (2003, p.116) afirma que a dignidade é concretizada através da igualdade, da liberdade (vontade livre e autodeterminação), da integridade física e moral e da solidariedade. Em verdade, a dignidade “[...] implica uma obrigação geral de respeito pela pessoa (pelo seu valor intrínseco como pessoa), traduzida num feixe de deveres e direitos correlativos, de natureza não meramente instrumental, mas sim relativos a um conjunto de bens indispensáveis ao "florescimento humano"”. (SARLET, 2007 apud GONÇALVES LOUREIRO, p.281).

Ademais, o art. $1^{\text {o }}$ da Declaração Universal da ONU (1948) afirma que "todos os seres humanos nascem livres e iguais em dignidade e direitos". Nesse sentido, importa frisar que todos são iguais, mesmo que infames, ou, até mesmo, absolutamente incapazes (SARLET, 2007, p. 366368). No entanto, mesmo que cientes de que todos têm o direito ao tratamento digno, ainda assim não é possível universalizar condutas, uma vez diante das disparidades culturais que variam de acordo com o local e a época.

Nessa contextualização da dignidade da pessoa humana, torna-se visível a importância do direito à desconexão para garantir a aplicação e a manutenção do princípio da dignidade. $\mathrm{O}$ poder diretivo do empregador numa situação de intensa conectividade pode sujeitar o empregado aos excessos que degradam e violam a vida saudável e o bem-estar físico, emocional e social citados anteriormente.

\subsection{Intimidade e Privacidade}




\section{DIREITO À DESCONEXÃO DO TRABALHO FRENTE A UMA SOCIEDADE HIPERCONECTADA}

Previsto no art. $5^{\circ}$, inciso $\mathrm{X}^{7}$, da Constituição, a intimidade e a privacidade são direitos de personalidade, cuja natureza é extrapatrimonial, que se aproxima intimamente com a valorização da dignidade da pessoa humana a fim de defender os valores inerentes ao homem, sendo ele indisponível, intransmissível irrenunciável ${ }^{8}$ e de complexa estimação pecuniária (NASCIMENTO, 2010, p. 716-717).

Na Conferência Nórdica sobre o Direito à Intimidade, ocorrida em 1967, em Estocolmo, foram elencadas cinco ofensas ao direito à intimidade. Entre ela, uma claramente cabível no contexto deste artigo: "penetração no retraimento da solidão da pessoa, incluindo-se no caso o espreitala pelo seguimento, pela espionagem ou pelo chamamento constante ao telefone" (CUNHA JÚNIOR, 2015, p. 572).

Afirma Fernandes (1977, p. 158-159) que a intimidade se concretiza quando o homem possui um local em que possa fechar as portas e ter a certeza de que está a salvo da presença daquilo que não deseja, dos intrusos incômodos e de observações indesejadas, pelo menos em determinados momentos.

A intimidade finda preservar as questões íntimas e privadas, referindo-se à essência do indivíduo e à sua personalidade (CUNHA JÚNIOR, 2015, p. 573). Trata-se de um direito de personalidade e a inserção do trabalhador no ambiente de trabalho não lhe retira este direito. A subordinação ou o poder diretivo não justificam a ineficácia do direito à intimidade no local de trabalho, admitindo-se apenas a modulação dos direitos fundamentais na medida imprescindível para o correto desenvolvimento da atividade laboral (RUIZ MIGUEL, 1995, p. 185).

A vida privada é menos secreta em comparação à intimidade. Diz respeito à sua vida em família, seu relacionamento com os amigos, e outras questões que também exigem uma certa reserva (CUNHA JÚNIOR, 2015, p. 573). O autor Silva Neto (2005, p. 92) afirma que a utilização cada vez mais intensa de bip's, telefones celulares e uso da internet tem gerado maior atenção por parte da doutrina ao estudo da vida privada dos trabalhadores, porque esses meios eletrônicos têm subtraído e limitado os momentos de lazer.

\footnotetext{
7 "São invioláveis a intimidade, a vida privada, a honra e a imagem das pessoas, assegurado o direito à indenização pelo dano material ou moral decorrente de sua violação".

8 O Código Civil (Lei n. 10.406/2002) dispõe sobre direito de personalidade em seus artigos 11 a 21. Especificamente no art. 11, ele declara serem indisponíveis e irrenunciáveis, conforme segue: "Art. 11:-Com exceção dos casos previstos em lei, os direitos da personalidade são intransmissíveis e irrenunciáveis, não podendo o seu exercício sofrer limitação voluntária". BRASIL, Código Civil. Disponível em: <http://www.planalto.gov.br/ccivil_03/leis/2002/L10406.htm〉. Acessado em 03 ago. 2017.
} 
Para Souto Maior (2003, p. 18), enquanto na análise do direito à desconexão, assim como o trabalho não pode intervir na vida privada do trabalhador, a vida privada não pode interferir na atividade laboral. O bom senso e a razoabilidade são indispensáveis para que cada caso seja avaliado individualmente a fim de garantir ao empregado a sua privacidade e ao empregador a prestação de serviços adequada, conforme qualidade e quantidade a que o trabalhador se comprometeu por contrato (SOUTO MAIOR, 2003, p. 18).

\subsection{Direito ao lazer}

O direito ao lazer é previsto no art. $24^{9}$ da Declaração Universal dos Direitos Humanos e no art. $7^{\circ}$, XIII da $\mathrm{CF}^{10}$. O direito ao lazer também está presente no art. $6^{\circ}$ da Constituição ${ }^{11}$ como um direito social, assim como está o trabalho. O lazer é um direito essencial para garantia da qualidade de vida do empregado e também pode ser compreendido como folga, descanso, tempo livre, repouso e até mesmo o direito de não trabalhar (SOUTO MAIOR, 2003, p. 01).

Sabe-se que os estudos da medicina do trabalho norteiam e fundamentam a legislação que aplica o limite da jornada de trabalho, garantindo um equilíbrio entre os períodos trabalhados com a “prestação da energia posta à disposição dos fins da empresa, de modo a utilizá-la em três planos de aproveitamento - orgânico, social e econômico" e os repousos do trabalhador (RODRIGUES PINTO; PAMPLONA FILHO, 2000, p. 452).

É imprescindível falar da limitação da jornada de trabalho quando se pretende abordar o direito ao lazer. Nessa lógica, tem-se que os repousos de pequenos intervalos ou dia(s) alcançam um resultado físico necessário para que o organismo humano se recomponha e suporte a continuidade da atividade a ser realizada com qualidade. Enquanto isso, os repousos semanais alcançam um resultado social imediato por permitirem o afastamento do trabalhador àquela responsabilidade cotidiana, proporcionando a convivência familiar e social. (RODRIGUES PINTO e PAMPLONA FILHO, 2000, p. 452).

\footnotetext{
9 “Toda pessoa tem direito a repouso e lazer, inclusive a limitação razoável das horas de trabalho e férias periódicas remuneradas."

${ }^{10}$ XIII - "duração do trabalho normal não superior a oito horas diárias e quarenta e quatro semanais, facultada a compensação de horários e a redução da jornada, mediante acordo ou convenção coletiva de trabalho"; XV "repouso semanal remunerado, preferencialmente aos domingos"; XVI - "remuneração do serviço extraordinário superior, no mínimo, em cinquenta por cento à do normal"; entre outros.

11 "São direitos sociais a educação, a saúde, a alimentação, o trabalho, a moradia, o lazer, a segurança, a previdência social, a proteção à maternidade e à infância, a assistência aos desamparados, na forma desta Constituição".
} 


\section{DIREITO À DESCONEXÃO DO TRABALHO FRENTE A UMA SOCIEDADE HIPERCONECTADA}

Lamentavelmente, aos olhos de grande parte dos empregadores esses direitos, tais como os previstos no art. $7^{\circ}$ da Constituição, ainda são excessivamente onerosos. No entanto, o exercício do repouso assegura as garantias do empregado (direito ao lazer, à intimidade e à vida privada) e impede que o empregador tenha problemas futuros com atividades mal desempenhadas, acidentes de trabalho ou prejuízos maiores devido ao esgotamento da capacidade física e mental do trabalhador (GOMES, 2015, p.11).

Vólia Bomfim Cassar (2011, p. 653) concorda que a duração do trabalho ultrapassa a esfera jurídica e encontra fundamentos em outros aspectos importantes. Numa acepção biológica, a quantidade excessiva de trabalho diário causa fadiga, estresse e cansaço que ferem a saúde física e mental. Já no fator social, a ausência de tempo de descanso isola o trabalhador socialmente e afeta negativamente seu contato com familiares e amigos, já que não dispõe de tempo para tanto. Por fim, o fator econômico apresenta desvantagens uma vez que o trabalhador que possui os sintomas negativos do fator biológico (fadiga, estresse e cansaço) produz pouco e não tem tempo para consumir.

Nesse sentido, Almeida, Severo (2016, p. 15) discorrem que "a empresa tem na limitação da jornada, portanto, não apenas um elemento de garantia de renovação da força de trabalho, como também a possibilidade de que os trabalhadores, além de produzir, consumam as mercadorias e serviços oferecidos". A limitação da jornada é uma opção para uma "sociedade de pessoas saudáveis, que tenham tempo de interagir e intervir na construção de um mundo melhor" (ALMEIDA, SEVERO, 2016, p. 15).

Explica De Masi (2000, p. 329) que para cada um o tempo livre significa "viagem, cultura, erotismo, estética, repouso, esporte, ginástica, meditação e reflexão" o que é, em suma, "dar sentido às coisas de todo o dia, em geral lindas, sempre iguais e sempre diversas, que infelizmente sã depreciadas pelo uso cotidiano".

O lazer é uma necessidade, pois uma sociedade que trabalha em tempo integral "é uma sociedade sem perspectivas de verdadeira melhoria das condições sociais" porque as extensas jornadas de trabalho causam esgotamento físico e mental, afastamento do convívio social, ocasionando doenças e morte prematura, desconstituindo a proteção à higidez do trabalhador. (ALMEIDA, SEVERO, 2016, p. 14). Destaca-se que a limitação da jornada de trabalho para concessão do tempo de lazer ao empregado não afronta os interesses do empregador. 
A desconexão, conquistada também através do lazer, atende aos interesses do trabalhador, do empregador e da sociedade pretendendo desenvolver o indivíduo que socializa, convive e evolui. Nessa perspectiva, mesmo que garantido o direito ao lazer para o trabalhador, o mau uso desse momento disponibilizado para descanso anula a "obra social e cultural" que se pretendia com a limitação da duração do trabalho (SUSSEKIN e MARANHÃO, 1991, p. 701 apud ALMEIDA, SEVERO, 2016, p. 15).

\section{DOENÇAS OCASIONADAS PELA HIPERCONECTIVIDADE}

As mudanças sociais, culturais e tecnológicas são contínuas e vêm ocorrendo de forma rápida e intensa. A impossibilidade de acompanhá-las no mesmo ritmo em que ocorrem, gera ansiedade e angústias que afetam diretamente a saúde física e mental. Especialista em endodontia, o médico Luiz Roberto Fava (2015, p.02) afirma que o estresse causado pela falta de tempo, trânsito caótico, condições de trabalho e o uso intensificado das tecnologias são alguns dos principais causadores das doenças da atualidade.

O médico FAVA (2015, p. 03) garante que já é possível afirmar com certeza sobre alguns fatos relacionados à dependência pelo uso das tecnologias que é um fenômeno global. Entre os dados obtidos até então, estima-se que 5\% dos jovens possuem algum distúrbio causado pelo uso intenso das tecnologias, considerando que as meninas se conectam mais intensamente às redes sociais e, os meninos, devido aos jogos on line, apresentam maiores problemas.

Os jovens apresentam uma piora importante no rendimento escolar, isolamento social, conflitos familiares, aumento de peso devido ao sedentarismo e dores lombares. Esses problemas estão, normalmente, relacionados à depressão, ansiedade, déficit de atenção, hiperatividade e agressividade. Tem-se a certeza de que o uso intenso das tecnologias não é apenas uma fase e tende a se intensificar com o tempo. Diante disso, o médico elenca algumas doenças causadas pelo uso excessivo das tecnologias (FAVA, 2015, p. 03).

A nomofobia é o medo de ficar sem o celular, independentemente do motivo que pode ser o término da bateria, ou até mesmo o esquecimento do celular em algum local. Os nomofóbicos apresentam impaciência, impulsividade e ansiedade que, por vezes, aparecem em forma de tremores, suor excessivo e dor de cabeça. A nomofobia diminui o convívio social e familiar do 
indivíduo porque ele se sente mais seguro nos relacionamentos virtuais e pode até mesmo se sentir rejeitado na ausência da comunicação e correspondência virtual (FAVA, 2015, p. 03).

O Opthalmology Journal publicou uma pesquisa afirmando que até 2050, em torno de 4,8 bilhões de pessoas, o que corresponde a $49,8 \%$ da população mundial, terão alguma deficiência visual e irão depender do uso de óculos. O crescimento de deficiência visual é resultado direto da exposição desmedida às telas dos aparelhos eletrônicos. Para que se possa ter dimensão do crescimento do problema, em 2010, aproximadamente 2 bilhões de pessoas $(28,3 \%$ da população mundial) sofriam com problemas visuais (50\%..., 2016, s.p.).

Insônia e problemas auditivos também são recorrentes. Os adolescentes permanecem conectados durante grande parte do dia e da noite e dormem, muitas vezes, com o celular próximo ao lado e até mesmo em baixo do travesseiro, o que interfere diretamente na qualidade do sono (FAVA, 2015, p. 04).

A dependência pelo aparelho celular também faz com que algumas pessoas desenvolvam a sensação de senti-lo vibrando, mesmo quando ele não está, o que é chamado de "Síndrome da vibração fantasma". Por fim, a lesão por esforço repetitivo também é elencada entre uma das doenças mais recorrentes em função do uso das tecnologias. A digitação em computadores e aparelhos celular, as vezes usando apenas os polegares desenvolve até mesmo artrite (FAVA, 2015, p. 04). A fim de reafirmar sua preocupação com o uso atenuante das tecnologias, FAVA (2015, p. 05) afirma que:

[...] toda essa tecnologia deve vir em nosso auxílio para implementar e agilizar nossas tarefas. A tecnologia deve ser nossa "escrava" e não o oposto, onde as pessoas estão sendo escravizadas por ela. Devemos extrair dela tudo que pode vir a nosso favor, não o que nos deixa viciados, dependentes e doentes. A tecnologia deve nos ajudar a viver melhor e não pior.

Para não se tornar "escravos" da tecnologia, o médico orienta a desconexão completa por um determinado tempo e a realização de atividades desassociadas à tecnologia. As caminhadas, idas ao cinema, teatro, galerias de arte, jogos e brinquedos que exijam concentração estão entre as tarefas indicadas pelo especialista. 


\section{CONTEXTUALIZANDO O DIREITO À DESCONEXÃO}

Embora não seja novo, o Direito à Desconexão vem há pouco tempo ganhando espaço para ser debatido e compreendido como um direito fundamental. Portanto, a tentativa de definição é sempre aberta, sujeita a alterações (ALMEIDA, SEVERO, 2016, p.37). A expressão está intimamente ligada à limitação da jornada de trabalho que tem sido ainda mais dificultada pelo uso das tecnologias penetrantes e invasoras no ambiente de labor.

O autor De Masi (2000, p. 184) afirma que os computadores, fax e máquinas fotocopiadoras são inovações que modificaram as atividades realizadas exclusivamente dentro da empresa. A internet modifica tudo: o que é feito dentro da empresa e a vida do trabalhador fora dela:

O trabalho oferece sobretudo a possibilidade de ganhar dinheiro, prestígio e poder. $\mathrm{O}$ tempo livre oferece sobretudo a possibilidade de introspecção, de jogo, de convívio, de amizade, de amor e de aventura. Não se entende por que o prazer ligado ao trabalho deveria acabar com a alegria do tempo livre (DE MASI, 2000, p. 328).

Afirmam Almeida, Severo (2016, p. 38) nessa perspectiva, que a "Nossa realidade atual impõe extrema conexão, vinte e quatro horas por dia, sete dias por semana. Daí a atualidade do tema e sua premência. As regras de proteção ao lazer (ou à desconexão), e bem assim, de limitação da jornada, não são novidades.”.

O direito à desconexão está positivado em tratados internacionais e, inclusive, no ordenamento jurídico pátrio, por meio da Constituição e normais infraconstitucionais. Nesse sentido, é possível identifica-lo, por exemplo, através da leitura do artigo 24 da Declaração Universal dos Direitos do Homem ${ }^{12}$, do artigo $7^{\circ}$ do Pacto Internacional sobre os Direitos Econômicos, Sociais e Culturais ${ }^{13}$ e do art. $6^{\circ}$ da Constituição Federal ${ }^{14}$.

Argumenta Souto Maior (2003, p.01) que a pertinência da discussão está exatamente no encontro entre a tecnologia e o trabalho humano que gera quatro contradições: a primeira é a preocupação com o "não trabalho" numa sociedade em que o desemprego causa inquietude; a

\footnotetext{
12 "Toda a pessoa tem direito ao repouso e aos lazeres e, especialmente, a uma limitação razoável da duração do trabalho e a férias periódicas pagas.".

13 "Os Estados Partes do presente Pacto reconhecem o direito de toda pessoa de gozar de condições de trabalho justas e favoráveis, que assegurem especialmente: d) O descanso, o lazer, a limitação razoável das horas de trabalho e férias periódicas remuneradas, assim como a remuneração dos feridos.".

14 “São direitos sociais a educação, a saúde, a alimentação, o trabalho, a moradia, o lazer, a segurança, a previdência social, a proteção à maternidade e à infância, a assistência aos desamparados, na forma desta Constituição.”.
} 


\section{DIREITO À DESCONEXÃO DO TRABALHO FRENTE A UMA SOCIEDADE HIPERCONECTADA}

segunda é a duplicidade de entendimentos quanto à essa relação entre tecnologia e trabalho: ao mesmo tempo em que culpam o avanço tecnológico por roubar o trabalho do homem, a terceira contradição identificada está na possibilidade de informação infinita que a tecnologia proporciona: o homem pode manter-se informado e atualizado a todo tempo, mas torna-se escravizado enquanto não desconecta. Por fim, ainda sobre as contradições, o autor (SOUTO MAIOR, 2003, p. 01) recorda que a filosofia moderna e vários ordenamentos jurídicos afirmam que o trabalho dignifica o homem. No entanto, sob outro ângulo, é ele quem retira esta dignidade quando atinge a intimidade e a vida privada do empregado.

Os meios tecnológicos têm permitido que o empregador utilize as forças do trabalhador durante as 24 horas do dia. A respeito dessa percepção de trabalho, De Masi (2000, p. 176-177) explica o fenômeno do overtime, que, em inglês, significa "além do tempo", o que chamamos comumente de extraordinário: as horas realizadas além do tempo compactuado para a jornada de trabalho. $\mathrm{O}$ autor explica que, com o advento das tecnologias, alguns empregos desapareceram e muitos outros sofreram erosão. Para a grande maioria o trabalho diminuiu e poderia ser realizado no limite de cinco ou seis horas diárias, no entanto, alguns são sobrecarregados. Considerando que os executivos e dirigentes não possuem remuneração das horas extras, acredita-se existir uma tentação por parte dos altos escalões para prolongar o expediente realizado por estes trabalhadores (DE MASI, 2000, p. 176).

O trabalho que deveria ser reduzido progressivamente com o avanço das tecnologias e com a diminuição de trabalho, ocorre de forma inversa: os empregados permanecem nas empresas além do horário pactuado sem receber qualquer remuneração. De Masi (2000, p. 176) afirma: "Depois de um certo tempo, o overtime se torna uma exigência por parte do chefe. E, o que é pior, com o passar do tempo, se torna também uma dependência psicológica do empregado: ele se habitua a tal ponto a passar todo o dia no escritório, que, se saísse antes, se sentiria perdido, desorientado, inútil."

O autor De Masi (2000, p. 177) afirma que a empresa é, por natureza, uma instituição “onívora” e que deseja absorver o trabalho do homem em tempo integral:

É uma necessidade psicológica, semelhante à que liga a vítima ao seu carrasco. $\mathrm{O}$ chefe não consegue abrir mão dos empregados subordinados a ele, e estes, por sua vez, não conseguem abrir mão da subordinação do chefe.

O funcionário deve demonstrar ao chefe que o tempo não é suficiente, que tem muita coisa para fazer e que é tão prestimoso a fiel à empresa, que se dispõe a assumir todas essas tarefas no overtime, até mesmo gratuitamente. Portanto, sacrifica a família e o 
lazer a este mito que é a empresa, colocado em primeiro lugar, acima de qualquer coisa.

Como consequência dessa subordinação extrema e abusiva, o chefe torna a promoção, o aumento salarial e o simples relacionamento de confiança dependentes dessa fidelidade de doação do empregado à instituição (DE MASI, 2000, p. 177).

O excesso da jornada, assim como o uso desmoderado das tecnologias estão associados à depressão, suicídios e doenças. Por isso, a abordagem do tema não intenta apenas buscar regulação à utilização das novas tecnologias no labor, mas abordar a perspectiva de uma vida digna, saudável e prazerosa (ALMEIDA; SEVERO, 2016, p.39).

As palavras "lazer", "trabalho mental suave" e "repouso" podem ser encontradas como sinônimos de ócio e, a respeito dele, o autor Domenico De Masi (2000, p. 241) explica que "o ócio é necessário à produção de ideias e as ideias são necessárias ao desenvolvimento da sociedade". Refere-se aqui ao ócio criativo, na qual a mente permanece muito ativa e nos causa liberdade, felicidade e crescimento. O cinema, o teatro, os intervalos e as férias jamais serão tempo perdido porque são estímulos "para intuir coisas e compreender outras". De Mais (2000, p. 242) conta que "Foi uma cena do filme Beldades no Banho que sugeriu a Crick e Watson a hipótese de que a hélice do DNA pudesse ser dupla. Se não gostassem de cinema, talvez tivessem levado muito mais tempo para descobrir a estrutura tão pesquisada.”.

Sabe-se que "o aumento de potência da tecnologia é muito mais rápido do que a capacidade de invenção de novos empregos". Por isso, na década de 30, a mecanização dos meios de produção já era uma preocupação, à qual aliavam a redução extremada dos horários de trabalho e à necessária reeducação da sociedade quanto ao uso do tempo livre (DE MASI, 2000, p. 287).

Nesse sentido, DE MASI (2000, p. 29) afirma que, além da formação ética já oferecida, a nova geração necessita aprender sobre o não trabalho, o cultivo e o bom aproveitamento do tempo livre para viver bem, com sabedoria e de forma prazerosa. Interessa expor o posicionamento do autor (DE MASI, 2000, p. 29) no sentido de relacionar o mau uso do ócio à violência. Ele afirma que as notícias recorrentes sobre os jovens que violentam, assaltam ou cometem outras barbaridades, revelam que eles não tiveram uma formação para o bom uso do ócio, o que é imprescindível considerando que hoje, a sociedade em geral pertence muito mais ao tempo ócio do que ao labor. 


\section{DIREITO À DESCONEXÃO DO TRABALHO FRENTE A UMA SOCIEDADE HIPERCONECTADA}

Ou seja, o tempo livre não é só uma necessidade para o cultivo do lazer, nos casos em que desrespeitado os limites da jornada de trabalho, mas também é uma tendência com o advento das tecnologias. O autor De Masi (2000, p. 322-323) argumenta que, no ano de 2000, "a perspectiva existencial de um jovem de vinte anos é que o trabalho representará somente um sétimo da duração da sua vida" e afirma, com precisão, que "nos anos passados foi o trabalho que colonizou o tempo livre; nos anos futuros será o tempo livre a colonizar o trabalho".

Traduzido por Souto Maior como direito de não trabalhar, o direito à desconexão trata de uma perspectiva técnico-jurídica que visa identificar a "existência de um bem da vida, o nãotrabalho, cuja preservação possa se dar, em concreto, por uma pretensão que se deduza em juízo". Os titulares desse direito são, inclusive, os desempregados que não conquistam sua vaga em função do trabalho excessivo do outro (SOUTO MAIRO, 2003, p. 02).

A sociedade regulada pelo capitalismo, que implica "a troca de força de trabalho por remuneração e a legítima persecução de lucro pela empresa", (ALMEIDA; SEVERO, 2016, p.37) tem enraizada a percepção de que o trabalho identifica, dignifica e honra o homem, mantendo-o numa postura social diferenciada a quem não trabalha, apesar da consciência geral das dificuldades atuais para encontrar uma ocupação (SOUTO MAIOR, 2003, p. 02-03).

Nessa percepção Jorge Luiz Souto Maior (2003, p. 03) afirma que "impera, culturalmente, a ideia do trabalho como fator dignificante da pessoa humana e como elemento de socialização do indivíduo, tornando-se um grande desafio falar em direito ao não-trabalho, ainda mais sob o prisma da efetiva proteção jurídica deste bem".

No entanto, o não-trabalho a que o autor se refere é no sentido de limitar a atividade laboral para preservar a vida privada e a saúde, não significando a ausência total de trabalho. Se desligar concretamente do trabalho é uma preocupação estimulada pelas "características deste mundo do trabalho marcado pela evolução tecnológica, pela deificação do mercado e pelo atendimento, em primeiro plano, das exigências do consumo" (SOUTO MAIOR, 2003, p. 03).

Não se pretende com esta exposição que a tecnologia seja vista com maus olhos. No entanto, o grande desafio é que "a tecnologia esteja a serviço do homem e não contra o homem" (SOUTO MAIOR, 2003, p.03). Nesse sentido, o mesmo autor argumenta que:

A tecnologia fornece à sociedade meios mais confortáveis de viver, e elimina, em certos aspectos, a penosidade do trabalho, mas, fora de padrões responsáveis pode provocar desajustes na ordem social, cuja correção requer uma tomada de posição a 
respeito de qual bem deve ser sacrificado, trazendo-se ao problema, a responsabilidade social (SOUTO MAIOR, 2003, p. 03).

Torna-se necessário, portanto, o entendimento e a aplicação efetiva da desconexão a fim de garantir ao empregado o inestimável tempo de vida muitas vezes "furtado" pelo empregador através do uso descabido da tecnologia ou, simplesmente, desrespeitando os limites da jornada de trabalho (BARBIERO DA SILVA, 2015, p. 16).

Não se pode pensar que o pagamento diferenciado do salário quitaria a dedicação dessas horas a mais. A limitação da jornada de trabalho ultrapassa a questão financeira porque não é apenas um problema econômico, mas de saúde. O autor Souto Maior (2003, p.09) explica que a intenção do direito à desconexão não é gerar lucro com as extensas jornadas de trabalho, mas que essas jornadas exaustivas de trabalho não existam mais. Sabe-se que, as impossibilidades de controle concreto em alguns casos específicos geram a penalização econômica do empregador em favor do empregado, que acaba tendo caráter pedagógico ao pretender que os empregadores tomem medidas a fim de garantir o direito à desconexão (SOUTO MAIOR, 2003, p.09).

\section{CONSIDERAÇÕES FINAIS}

Esse artigo representa a preocupação com uso abusivo e descoordenado das novas tecnologias de comunicação que rompeu os limites e confundiu o labor e a vida pessoal dando origem ao termo "direito à desconexão". Intentou-se identificar as consequências causadas pelo excesso de trabalho e pela hiperconectividade a fim de justificar a importância e a aplicação do termo “direito à desconexão", problemáticas enfrentadas nesta pesquisa.

Com a conclusão da escrita é ainda mais notória a gravidade da exploração demasiada do tempo de vida. Trata-se, verdadeiramente, de uma escravidão contemporânea com jornadas extensas e conexão em tempo integral. Foi possível a compreensão do advento das tecnologias de informação e comunicação como protagonistas da globalização acelerada que ocorreu no fim do século XX, quando o mundo se integrou formando uma aldeia global.

O trabalho nada mais é do que um reflexo da sociedade em que se vive. Nesse sentido, demonstrou-se que a rapidez da vida contemporânea gerada pelas tecnologias invadiu por completo o ambiente de trabalho. Entre todas as tecnologias, foi a vinda da internet que, 


\section{DIREITO À DESCONEXÃO DO TRABALHO FRENTE A UMA SOCIEDADE HIPERCONECTADA}

principalmente, gerou a necessidade de evolução contínua, de controle incessante e de conexão ininterrupta. Essa cultura de exigência intensa e conectividade em tempo integral produziram consequências graves, que afetaram a dignidade, vida privada e o direito ao lazer do trabalhador - tais conceitos, propiciaram a compreensão da tamanha relação existente entre eles o direito à desconexão.

A abordagem da ocorrência de doenças indicou a necessidade urgente de devolver à sociedade o tempo livre e que, principalmente, ela delibere e reformule seus conceitos sobre trabalho e tecnologias, quanto aos seus limites, se reeducando para a vida contemporânea.

Verifica-se a gravidade da má gestão realizada quanto à limitação da jornada de trabalho e o mau uso das tecnologias. É evidente a importância da aplicação do direito à desconexão não só enquanto garantia judicial, mas através de medidas tomadas no ambiente de trabalho que possam reconhecer o trabalhador através da sua sensibilidade de ser humano e promover a desconexão saudável propiciando interação e cultura através de jogos, manutenção de bibliotecas e outras atividades em horários pré-determinados durante a jornada.

Conclui-se que o direito à desconexão precisa ser debatido e aplicado para que a duração do trabalho seja definitivamente limitada a fim de construirmos uma sociedade de indivíduos saudáveis, que usufrua de uma vida minimamente digna.

Sabe-se que o Direito não possui função originalmente transformadora na sociedade, mas se reveste de um caráter conservador que nos permite enxerga-lo como tal. Dessa maneira, a garantia do não trabalho através do Direito é um dos caminhos importantes para promover o debate e a ação.

O estudo pretende fornecer uma pequena contribuição sobre o tema "direito à desconexão", ainda pouco debatido. Nesse sentido, é possível desenvolver em pesquisa futura, a análise mais profunda do art. 62 da CLT, o estudo do dano moral ou existencial existente no desrespeito à desconexão, assim como a análise das situações enfrentadas pelos órgãos de fiscalização da Justiça do Trabalho (ou outra instituição) que, com toda certeza, revelariam um caos ainda maior. Outra possibilidade é a análise de uma quantidade maior de acórdãos que podem fornecer argumentações e entendimentos diversos sobre o direito à desconexão. 


\section{REFERÊNCIAS}

$50 \%$ da população mundial terá de usar óculos em 2050 por excesso de tecnologia. Canaltech. Disponível em: <https://canaltech.com.br/mercado/50-populacao-mundialtera-de-usar-oculos-em-2050-por-excesso-de-tecnologia-58553/>. Acesso em: 07 mai. 2018.

ALMEIDA, Almiro Eduardo de; SEVERO, Valdete Souto. Direito à desconexão nas relações sociais de trabalho. 2.ed. São Paulo: LTr, 2016.

BARBIERO DA SILVA, William. O Direito à Desconexão: um direito fundamental ao não-trabalho aplicável aos gerentes bancários. Porto Alegre: Femargs, 2015. Artigo apresentado como requisito parcial para obtenção do título de Pós-Graduação em Direito Material e Processual do Trabalho. Disponível em: < http://www.femargs.com.br/uploads/artigos/o-direito-a-desconexao-um-direitofundamental-ao-nao-trabalho-aplicavel-aos-gerentes-bancarios/o-direito-a-desconexaoum-direito-fundamental-ao-nao-trabalho-aplicavel-aos-gerentes-bancarios.pdf $>$. Acesso em: 10 abr. 2018.

BODIN DE MORAES, M. C. O Conceito de Dignidade Humana: Substrato Axiológico e Conteúdo Normativo. In: I. W. Sarlet (Org.). Constituição, Direitos Fundamentais e Direito Privado. Porto Alegre: Livraria do Advogado, 2003.

BRASI. Lei $\mathbf{n}^{\circ} \mathbf{8 . 2 1 3}$, de 24 de julho de 1991. Disponível em: < http://www.planalto.gov.br/ccivil_03/LEIS/L8213cons.htm>. Acesso em: 23 out. 2017

BRASIL. Pacto Internacional sobre Direitos Econômicos, Sociais e Culturais. Disponível em: < http://www.planalto.gov.br/ccivil_03/decreto/1990-1994/D0591.htm>. Acesso em: 10 mar. 2018.

CASSAR, Vólia Bomfim. Direito do Trabalho. 14 ed. Rio de Janeiro: Forense; São Paulo: MÉTODO, 2017.

Direito do Trabalho. 5. ed. Niterói: Impetus, 2011.

Flexibilização das normas trabalhistas. Rio de Janeiro: UGF, 2010. Tese (Doutorado em Direito e Economia). Universidade Gama Filho, 2010.

CUNHA JÚNIOR, Dirley. Curso de Direito Constitucional. 9ed. Editora Jus Podium, 2015.

DELGADO, Mauricio Godinho. Capitalismo, trabalho e emprego: Entre o paradigma da destruição e os caminhos de reconstrução. $2^{a}$ ed. São Paulo: Ltr, 2015.

Curso de direito do trabalho. 11 ed. São Paulo: LTr, 2012.

Curso de Direito do Trabalho. $7^{\mathrm{a}}$ edição. São Paulo: Ltr, 2008.

Curso de Direito do Trabalho. São Paulo: Ltr, 2002, p. 854, apud CASSAR, Vólia Bomfim. Direito do Trabalho. 14 ed. Rio de Janeiro: Forense; São Paulo: MÉTODO, 2017.

DE MASI, Domenico. O Ócio Criativo. Tradução De Léa Manzi. - Rio De Janeiro: Sextante, 2000. 
FAVA, Luiz Roberto. Doenças da modernidade tecnológica. Disponível em: <http://favaconsulting.com.br/doencas-modernidade-tecnologia/>. Acesso em: 07 mai. 2018.

FERNANDES, Milton. Proteção civil da intimidade. São Paulo: Saraiva, 1977.

INSTITUTO DE PESQUISA ECONÔMICA APLICADA. Comunicado da Presidência: Carga horária de trabalho: evolução e principais mudanças no Brasil. Disponível em:<http://www.en.ipea.gov.br/agencia/images/stories/PDFs/comunicado/090729_comun icadoipea24.pdf >. Acesso em: 13 abr. 2018.

NASCIMENTO, Amauri Mascaro. Curso de direito do trabalho: história e teoria geral do direito do trabalho: relações individuais e coletivas do trabalho. 25. ed. São Paula: Saraiva, 2010.

LTr, 2013.

Amauri Mascaro. Iniciação ao Direito do Trabalho. 38 ed. São Paulo:

NAZIAZENO, Érica Lima. A moderna sociedade tecnológica em confronto com o princípio fundamental do direito à desconexão ao trabalho. Disponível em: <https://jus.com.br/artigos/39736/a-moderna-sociedade-tecnologica-em-confronto-como-principio-fundamental-do-direito-a-desconexao-ao-trabalho>. Acesso em: 10 abr. 2018.

OLIVEIRA, Christiana D'arc Damasceno. Direito à desconexão do trabalhador repercussão no atual contexto trabalhista. São Paulo: LTr, 2010 apud NAZIAZENO, Érica Lima. A moderna sociedade tecnológica em confronto com o princípio fundamental do direito à desconexão ao trabalho. Disponível em: $<$ https://jus.com.br/artigos/39736/a-moderna-sociedade-tecnologica-em-confronto-como-principio-fundamental-do-direito-a-desconexao-ao-trabalho>. Acesso em: 10 abr. 2018.

ORGANIZAÇÃO DAS NAÇÕES UNIDAS (ONU). Declaração Universal de Direitos Humanos de $1948 . \quad$ Disponível em: <http://unesdoc.unesco.org/images/0013/001394/139423por.pdf>. Acesso em: 11 jul. 2018.

RODRIGUES PINTO, José Augusto. PAMPLONA FILHO, Rodolfo. Repertório de Conceitos Trabalhistas. São Paulo: LTr, 2000.

ROMITA, Aryon Sayão; Direitos fundamentais nas relações de trabalho. São Paulo: LTr, 2005.

SARLET, Ingo Wolfgang. As dimensões da dignidade da pessoa humana: construindo uma compreensão jurídico-constitucional necessária e possível. Revista Brasileira de Direito Constitucional, n. 09, jan./jun. 2007, p. 361-388.

SOUTO MAIOR, Jorge Luiz. Do Direito à Desconexão do Trabalho. Disponível em: <http://www.jorgesoutomaior.com/uploads/5/3/9/1/53916439/do_direito_\%C3\%A0_desc onex\%C3\%A3o_do_trabalho..pdf>. Acesso em: 28 mai. 2018.

Do direito à desconexão do trabalho. Revista do Tribunal Regional do Trabalho da 15 Região. Campinas, $\mathrm{n}^{\circ}$ 23, 2003. Disponível em: <http://trt15.gov.br/escola_da_magistratura/Rev23Art17.pdf>. Acesso em: 13 abr. 2018. 
Os 201 ataques da "reforma" aos trabalhadores. Disponível em: < http://www.jorgesoutomaior.com/blog/os-201-ataques-da-reforma-aos-trabalhadores>. Acesso em: 15 abr. 2018.

SÜSSEKIND, Arnaldo, MARANHÃO, Délio e VIANNA, Segadas. Instituições de Direito do Trabalho. 20a ed. São Paulo: LTr, 2002.

VALENTIM, João Hilário. Teletrabalho e relações de trabalho. Revista Gênesis de Direito do Trabalho. Curitiba: Gênesis, 1999, apud CASSAR, Vólia Bomfim. Direito do Trabalho. 14 ed. Rio de Janeiro: Forense; São Paulo: MÉTODO, 2017. 